IJAMSR 3 (6) www.ijamsr.com CrossRef: https://doi.org/10.31426/ijamsr.2020.3.6.3411

\title{
ANALYTICAL STUDY ON CAUSE OF STRESS AND ADJUSTMENT OF CHILDREN DUE TO MOVEMENT DISORDER
}

\section{Zeynab Binandeh}

Graduate, Research Sciences Department, Azad University of Urmia, Iran

Email: binandehzeynab@gmail.com

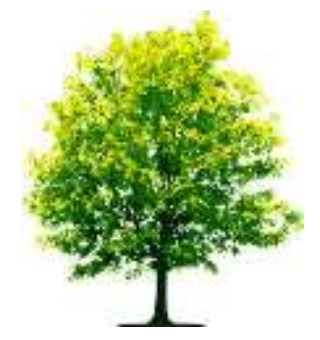

Keywords:

Movement Disorder,

Stress,

Adjustment,

\begin{abstract}
A B S T R A C T
Movement disorders allude to a cluster of central nervous system diseases and syndromes which horribly affects the creation and control of body movements. Psychological stress among children's occurs when they see that the demands from their condition outstrip their versatile limit. The studies on stress focus either on the event of natural events that demands one's capacity to deal with singular responses to events. Children's with movement disorders experience physical which may prompt severe tension or depression.
\end{abstract}

Citation: Zeynab Binandeh (2020). Analytical Study On Cause Of Stress And Adjustment Of Children Due To Movement Disorder. International Journal of Advanced Multidisciplinary Scientific Research (IJAMSR) ISSN:2581-4281, 3 (6), June 2020, Pp 1 - 10 
IJAMSR 3 (6) www.ijamsr.com CrossRef: https://doi.org/10.31426/ijamsr.2020.3.6.3411

\section{International Journal of}

Advanced Multidisciplinary Scientific Research (IJAMSR) ISSN:2581-4281

\section{Introduction}

The pattern of advancement of movement disorders generally includes progressive subjective and utilitarian declines in the influenced children. The degree of movement disorders in various diseases may contribute significantly to the general bleakness on the influenced, underscoring the significance of recognizing and measuring psychosocial problems like stress associated with the movement disorder and their adjustment design. Movement disorders can severely compromise a children's's capacity to perform activities of day by day living. Such societies are portrayed by low levels of awareness in regards to stress and adjustment among individuals with movement disorders and by an absence of supportive emotional wellness and government assistance service.

Stress refers to any circumstances that threatens or saw to compromise one's prosperity and that accordingly charge one's adapting abilities. In the present study, stress means and is represented by the scores acquired for the stress scale which indicates the subjective impression of the children's stress reactions in terms of their stress appraisal or enthusiastic response among children's or children's with movement disorders.

Adjustment refers to the changes in life that are made continuously when one has an incessant illness. Adjustment is not static, however unique. In this study adjustment means, and is represented by the scores acquired for the adjustment scale created by the investigator which indicates the capacity to satisfy the demands of one's surroundings as well as one's specific needs, so it is a solid harmony between what a children's wants and what the earth demands.

\section{Literature Review}

Awat Feizi, Badroddin Najmi, Aseih Salesi, Maryam Chorami, and Rezvan Hoveidafar (2014) Parents of children with developmental problems are always bearing a store of stress. The purpose of this study is to take a gander at the stress in mothers of children with various disabilities to each other, considering their segment establishment. This was a crosssectional study drove in Isfahan, Iran during 2012 on 285 mothers of 6-12 years old children with ceaseless physical disease, psychological disorder, and sensory-motor and mental problems. 
IJAMSR 3 (6) www.ijamsr.com CrossRef: https://doi.org/10.31426/ijamsr.2020.3.6.3411

Michael O Ogundele (2018) Psychological prosperity problems in children and adolescents join several types of enthusiastic and social disorders, including disruptive, depression, uneasiness and pervasive developmental (autism) disorders, described as either disguising or externalizing problems. Disruptive social problems such as hissy fits, consideration shortfall hyperactivity disorder, oppositional, rebellious or direct disorders are the commonest lead problems in preschool and school age children.

Neil Schneiderman, Gail Ironson, and Scott D. Siegel (2008) Stressors have a significant effect upon mentality, our sense of prosperity, lead, and prosperity. Intense stress responses in young, sound individuals may be versatile and ordinarily don't impose a prosperity inconvenience. In any case, if the risk is unremitting, especially in increasingly seasoned or shocking individuals, the drawn out effects of stressors can hurt prosperity. The relationship between psychosocial stressors and disease is affected by the nature, number, and persistence of the stressors as well as by the children's's natural weakness (i.e., genetics, constitutional factors), psychosocial resources, and scholarly patterns of adjusting.
Psychosocial interventions have demonstrated useful for remunerating stress-related disorders and may affect the course of constant diseases.

Gupta and Kaur. (2010) in their research on" Stress among parents of children with scholarly disability" took one hundred and two parents, thirty of whom had children without disability. $\mathrm{T}$ test was applied to test differences in stress, sex contrast and distinction in mental and physical stress. Most parents of children with scholarly disability experience stress. Physical and mental stress was seen as significantly related.

Ramya Bhaskar, Rudramma and M. Komala (2014) in present study an undertaking has been made to understand the relationship between the level of stress and adjustment among adolescents significantly significant sex distinction was shown with respect to home and social adjustment areas. Significantly significant association was seen among stress and social, enthusiastic and absolute adjustment areas. Adolescents have displayed a fluctuating degree of adjustments patterns by goodness of stress may be because of social insecurity, absence of good support, monetary backwardness, inadequate instructor 
IJAMSR 3 (6) www.ijamsr.com CrossRef: https://doi.org/10.31426/ijamsr.2020.3.6.3411

association, increased companion pressure, lower self esteem and self conviction, etc.

\section{Methodology}

The investigator received irregular sampling technique to ensure the right representation of the populace. For the direct of the study, the investigator selected 142 children's with movement disorders between the age of 10 to 15 institutions of Kottayam, Ernakulam, Alappuzha and Trissur districts of Kerala. The sample comprised of 82 male and 60 female children's from both urban and country zone.

\section{Tools}

The following tools were used for the present study.

- Proforma of Movement Disorders

- Activities of Daily Living inventory for children's with Movement Disorders (ADLI)

- Movement Disorders Stress Scale (MDSS)

- Adjustment to Movement Disorders Scale (AMDS)

\section{Movement Disorders Stress Scale (MDSS)}

Stress is an inescapable piece of regular day to day existence especially for children's with illnesses. Movement disorders may constrain the useful degree of the influenced children's which may prompt raised levels of stress. The MDSS was created by the investigator to measure the stress among children's with movement disorders.

\section{Adjustment to Movement Disorders Scale (AMDS)}

Adjustment means suitable adjustment or maintains balance in the earth. Adjustment to movement disorders implies the adjustment of a children's with movement disorders with their conditions caused by the disorder. ADMS was designed to measure the degree of adjustment of a children's with movement disorders in various situations. The AMDS provides the most uniform, legitimate and dependable measure of adjustment of children's with movement disorders.

\section{Analysis \& Results}

Level of Stress for the Socio-Economic (SE) aspect in MDSS among children's with movement disorders based on gender. 
IJAMSR 3 (6) www.ijamsr.com CrossRef: https://doi.org/10.31426/ijamsr.2020.3.6.3411

\section{International Journal of}

Advanced Multidisciplinary Scientific Research (IJAMSR) ISSN:2581-4281

The test of significance of stress in SE score based on sexual orientation were subjected to't' esteem analysis and organized as shown underneath.

Table 1 the results of test of significance of stress w.r.to SE aspect based on gender.

\begin{tabular}{|c|c|c|c|c|}
\hline Gender & Mean & SD & $\mathrm{N}$ & $\mathrm{t}$ \\
\hline Male & 29.8 & 6.0 & 82 & $6.02 * *$ \\
\hline & & & & \\
\cline { 1 - 3 } Female & 34.7 & 2.5 & 60 & \\
\hline
\end{tabular}

The results of the comparison of stress related to socioeconomic status based on gender uncovered that, among males, the mean and SD is 29.8 and 6.0 and that of females are 34.70 and 2.50. The free ' $t$ ' test $(6.02, \mathrm{p}<0.01)$ shows that the mean score of stress identified with socioeconomic status significantly differs among male and female. It is induced that the female and male children's with movement disorder were significantly varied in their socioeconomic aspect of stress. This indicates females with movement disorders have more stress identified with socioeconomic status than their male counterparts.

Level of stress for the aspect of socioeconomic status (SE) based age.
The test of significance of Stress in SE score based on age were subjected to't' esteem analysis and organized as shown beneath.

Table 2 the results of the test of significance of Stress w.r.to SE aspect based on age.

\begin{tabular}{|c|c|l|c|c|}
\hline Age & Mean & SD & N & t \\
\hline $5-10$ & 33.1 & 5.2 & 86 & $3.62^{* *}$ \\
\hline & & & & \\
\cline { 1 - 3 } & & & \\
& & & & \\
\end{tabular}

The results of the comparison of two groups of children's with movement disorders based on age in stress identified with socioeconomic status uncovered a significant contrast $(\mathrm{t}=3.62)$ between the age group 5-10 and 10-15. Children's with MD in the age group 5-10 is found to have a higher mean score (Mean = 33.1) than the children'ss with MD in the age group $10-15($ mean $=29.9)$. It is derived that children's with movement disorders among the age groups 5-10 and 10-15 had a significant distinction in stress identified with sociomonetary aspect. The higher mean score acquired for children's with $\mathrm{MD}$ in the age group 40-50 demonstrate a more elevated level of stress identified with the socio-financial aspect. 
IJAMSR 3 (6) www.ijamsr.com CrossRef: https://doi.org/10.31426/ijamsr.2020.3.6.3411

Level of stress for the aspect of socioeconomic status (SE) based on the degree of movement disorders

The test of significance of Stress in SE score based on degrees of movement disorder was subjected to ANOVA and post hoc test and classified as shown beneath.

Table 3 Summary of ANOVA and Post hoc Test with Scheffe Multiple Comparisons of Socioeconomic status aspect based on Degree of movement disorders.

\begin{tabular}{|c|c|c|c|c|c|c|c|}
\hline $\begin{array}{c}\text { Degrees of movement } \\
\text { disorders }\end{array}$ & Mean & SD & $\mathrm{N}$ & \multicolumn{2}{|c|}{$\mathrm{F}$} & \multicolumn{3}{|c|}{$\begin{array}{c}\text { Scheffe Multiple } \\
\text { Comparisons }\end{array}$} \\
\hline & & & & & Pair & $\mathrm{F}$ & $\mathrm{P}$ \\
\hline Mild (A) & 35.5 & 3.0 & 53 & & A \&B & $17.2^{* * *}$ & 0.000 \\
\hline Moderate (B) & 30.8 & 5.4 & 67 & $37.68^{* *}$ & A \& C & $33.8^{* *}$ & 0.000 \\
\hline Severe (C) & 26.4 & 3.4 & 22 & & B \& C & $8.4^{* *}$ & 0.000 \\
& & & & & & & \\
\hline
\end{tabular}

Different comparisons of the groups of children'ss with movement disorders based on the level of movement disorders were made to discover which groups vary from each other. The F-estimation of the mean score with respect to the socioeconomic aspect of stress $(F=37.68, p<0.01)$ vary significantly among the level of movement disorders. From the table, it very well may be seen that the mean score in regards to SE aspect of stress is high among children's with a gentle level of MD (mean score $=35.5)$ trailed by moderate (30.8) and least among severe (26.4). The highest mean score for SE aspect of stress was gotten by the children's with gentle MD and the lowest mean score was acquired by children's with severe MD.

Scheffe various comparisons (Post hoc Test) was used to think about the mean scores in regards to SE aspect of the stress of MD among various groups taken two at once (pair wise) to assess whether a significant mean contrast exists. $F^{\prime}$ Value $\left(F^{\prime}=17.2, p>0.05\right)$ shows that the SE aspect of stress does vary between children's with a mellow and moderate level of MD. It can also be observed that the mean score of children's with moderate MD is 
IJAMSR 3 (6) www.ijamsr.com CrossRef: https://doi.org/10.31426/ijamsr.2020.3.6.3411

significantly higher than the severe $\left(\mathrm{F}^{\prime}=33.8\right.$ $\mathrm{p}<0.01)$ and the score is significantly high for children's with mellow MD than severe $\left(F^{\prime}=8.4, p<0.01\right)$. Thus, it very well may be surmised that the SE aspect of stress is significantly high for children's with mellow MD and moderate MD when contrasted with children's with the severe level of MD.
Level of adjustment for the aspect adjustment to health care based on gender

The test of significance of Adjustment in Health Care (AHC) aspect based on sexual orientation were subjected to ' $t$ ' esteem analysis and classified as shown beneath.

Table 4 the results of the test of significance of adjustment to health care aspect based on gender.

\begin{tabular}{|c|c|c|c|c|c|}
\hline Category & & Mean & SD & N & t \\
\hline \multirow{3}{*}{ Gender } & Male & 75.2 & 7.7 & 82 & $4.61^{* *}$ \\
\cline { 2 - 5 } & & & & \multirow{2}{*}{} \\
\cline { 2 - 5 } & Female & 81.4 & 8.3 & 60 & \\
\hline
\end{tabular}

The results of the comparison of level of adjustment identified with AHC based on sexual orientation, uncovered that, among females, the mean and SD are 81.4 and 8.3 and that of males are 75.2 and 7.7. The free 't' test (4.61, $\mathrm{p}<0.01)$ shows that the mean score of adjustment identified with AHC aspect significantly contrast among male and female.
This indicates females with movement disorders have more adjustment identified with $\mathrm{AHC}$ aspect than their male counterparts.

Level of adjustment for the aspect adjustment to health care based on age

The test of significance of Adjustment in Health care aspect based on age were subjected to ' $\mathrm{t}$ ' esteem analysis and arranged as shown underneath. 
IJAMSR 3 (6) www.ijamsr.com CrossRef: https://doi.org/10.31426/ijamsr.2020.3.6.3411

Table 5 the results of the test of significance of adjustment to health care aspect based on age

\begin{tabular}{|l|l|l|l|l|l|}
\hline Category & & Mean & SD & N & t \\
\hline \multirow{3}{*}{ Age } & $5-10$ & 81.1 & 9.1 & 86 & $6.47 * *$ \\
\cline { 2 - 5 } & & & & & \\
\cline { 2 - 5 } & $10-15$ & 72.8 & 4.2 & 56 & \\
\hline
\end{tabular}

The results of the comparison of two groups of children's with movement disorders based on age in adjustment identified with AHC aspect uncovered significant contrast $(\mathrm{t}=6.47)$ between the age group 5-10 and 10-15. Children'ss with MD in the age group 5-10 is found to have a higher mean score (Mean = 81.1) than the children'ss with MD in the age group 10-15 (Mean score $=72.8$ ). It is gathered that children'ss with movement disorders among the age groups 5-10 and 10-15 had significant distinction in adjustment identified with AHC. The higher mean score got for children'ss with MD in the age group 5-10 demonstrate more significant level of adjustment identified with AHC aspect.

Level of adjustment for the aspect adjustment to health care based on degree of movement disorders
The test of significance of adjustment to medicinal services based on degrees of movement disorder were subjected to ANOVA and post hoc test and organized as shown underneath. 
IJAMSR 3 (6) www.ijamsr.com CrossRef: https://doi.org/10.31426/ijamsr.2020.3.6.3411

Table 6 Summary of ANOVA and Post hoc Test with Scheffe Multiple Comparisons of the aspect adjustment to health care based on degree of movement disorders.

\begin{tabular}{|c|c|c|c|c|c|c|c|}
\hline $\begin{array}{c}\text { Degrees of } \\
\text { movement } \\
\text { disorders }\end{array}$ & Mean & SD & N & \multicolumn{2}{|c|}{ F } & \multicolumn{3}{|l|}{ Scheffe Multiple Comparisons } \\
\cline { 2 - 8 } & & & & & Pair & $F^{\prime}$ & P \\
\hline Mild (A) & 87.0 & 4.6 & 53 & & A \&B & $139.5^{* *}$ & 0.000 \\
\hline Moderate (B) & 72.5 & 5.4 & 67 & $160.74^{* *}$ & B \& C & 0.2 & 0.819 \\
\hline Severe (C) & 71.8 & 1.9 & 22 & & A \& C & $80.9^{* *}$ & 0.000 \\
\hline
\end{tabular}

Scheffe various comparison (Post hoc Test)

Different comparisons of the groups of children's with movement disorders based on level of movement disorders were made to discover which groups vary from each other. The F-estimation of the mean score with respect to AHC aspect of adjustment $(\mathrm{F}=160.74, \mathrm{p}<0.01)$ vary significantly among the level of movement disorders. From the table it tends to be seen that the mean score in regards to AHC aspect of adjustment is high among children's with mellow level of MD (mean score $=87.0$ ) trailed by moderate $(72.5)$ and least among severe (71.8). The highest mean score for AHC aspect of adjustment was gotten by the children's with gentle MD and the lowest mean score was acquired by children's with severe MD. was used to think about the mean scores with respect to $\mathrm{AHC}$ aspect of adjustment of $\mathrm{MD}$ among various groups taken two at once (pair wise) to assess whether a significant mean contrast exist. $\mathrm{F}^{\prime}$ Value $\left(\mathrm{F}^{\prime}=139.5, \mathrm{p}>0.05\right)$ shows that the AHC aspect of adjustment does vary between children's with mellow and moderate level of MD. It can also be observed that there is no significant distinction in AHC aspect of adjustment among moderate and severe $\mathrm{MD}\left(\mathrm{F}^{\prime}=0.2 \mathrm{p}<0.01\right)$ and mean score is significantly high for children's with mellow MD than severe $\left(F^{\prime}=80.9, p<0.01\right)$. Thus, it tends to be construed that the AHC aspect of adjustment is significantly high for children's with gentle $\mathrm{MD}$ and moderate $\mathrm{MD}$ when contrasted with children's with severe level of MD. 
IJAMSR 3 (6) www.ijamsr.com CrossRef: https://doi.org/10.31426/ijamsr.2020.3.6.3411

\section{Conclusion}

Stress and adjustment among children's with movement disorders is one of the not many psychological studies led in the territory. The findings of the study have given significant data about the stress, adjustment and activities of day by day living skills of children's with movement disorders. The present study is designed to discover the nature, broaden and correlates of stress experienced by the individuals with movement disorders. Hypothetically, the study is relied upon to create and supplement a target understanding about the stress and adjustment among children's and individuals with movement disorders in terms of their socio segment profile. The finding of the present study has contributed significantly to the territory of psychological research on stress, adjustment movement disorders.

\section{References}

1) Awat Feizi, Badroddin Najmi, Aseih Salesi, Maryam Chorami, and Rezvan Hoveidafar (2014), 'Parenting stress among mothers of children with different physical, mental, and psychological problems', Journal ListJ Res Med Sciv.19(2); 2014 FebPMC3999601

2) Michael O Ogundele (2018), 'Behavioural and emotional disorders in childhood: A brief overview for paediatricians', Journal
ListWorld J Clin Pediatrv.7(1); 2018 Feb 8PMC5803568

3) Gupta, Raj Kumar \& Kaur, Harpreet (2010). Stress among parents of children with intellectual disability. Journal of Asia Pacific Disability Rehabilitation, 21(2)

4) Graetz, Janet E (2010). Autism grows: Opportunities for adults with autism. Journal of Disability and Society, 25(1), 33-47

5) Farheen, A., Dixit, S. \& Bansal, S.B. (2013). Stress perceived by families with mentally retarded children enrolled in special schools at Indore. JKpractitioner, 18(1-2).

6) Findler Liora (2014) The experiences of stress and children'sal growth among grandparents of children with or without intellectual disability. Intellectual and Developmental Disabilities.,52(1)32-48.

7) Levy Barak Yael.,Goldstein Esther.,Weinstok Michael (2010)Adjustment characteristics of healthy siblings of children with autism. Journal of Family Studies .16, 155.

8) Trute, Barry, Berzies, Karen M., \& Worthington, C. (2011). Mother positivity and family adjustment in household with children with a serious disability. Journal of Child and Family Studies, 21(3), 411417.

9) Dura-Vila, G., Dein, S., \& Hodes, M. (2010). Children with intellectual disability: A gains not a loss: Parental beliefs and family life. Journal of Clinical Psychology and Psychiatry, 15(2), 171184. Published online January 29, 2010 from http://ccp.sagepub.com/content/15/2/171

10) Ramya Bhaskar, Rudramma and $M$. Komala (2014), 'Study on Relationship between Stress and Adjustment among Adolescents', International Journal of Interdisciplinary and Multidisciplinary Studies (IJIMS), 2014, Vol 2, No.1, 62-67. 